\title{
Technology, Transaction Costs and Economic Foresight. Developing Tendency-Based Scenarios
}

\author{
Frank den Butter \\ VU University Amsterdam, \\ De Boelelaan 1105, $1081 \mathrm{HV}$, Amsterdam \\ The Netherlands \\ Patrick van der Duin \\ The Netherlands Study Centre for Technology Trends \\ Koninginnegracht 19, 2514 AB, The Hague \\ The Netherlands
}

\begin{abstract}
Combining historical economic data and positivistic, standard neoclassical economic theories does not give a sufficient nuanced view on different economic futures that address the future inherent uncertainty. Economic history does not repeat itself making economic systems 'open systems', and economic laws cannot be regarded as laws in the natural sciences. Therefore, we explore a different approach by taking critical realism as science-philosophical background, using transaction cost theory to cope with the unrealistic full rationality postulate of neoclassical economic theory. In particular, we use the scenario-method from the management sciences and use as the concept of 'tendencies', as developed within critical realism, as scenario-framework. To illustrate our approach we use the case of Sense Glove, a light, compact, and modular robotic hand shoe that was originally developed for cost-effective rehabilitation of hand paralysis, but which is now used to get a real sense of feeling objects in virtual and artificial reality.
\end{abstract}

Key words: transaction cost theory, scenarios, tendencies, critical realism, economic laws

\section{Introduction}

Prophets and fortunetellers except, we mortals do not have direct knowledge of the future. Our predictions of future developments invariably rely on knowledge of the past. In some disciplines, such as astronomy, there are lots of precise historical data and (almost) invariable laws, which make predictions of the future quite accurate (Hartmann, 2007). That holds for instance for the moments of sunrise and sunset, and for the positions and orbits of the sun, the moon, and the stars. However, such invariable laws do not exist in economics, which causes much uncertainty and discretion in views on the economic future. However, economic theory provides us with suggestions that historical relationships between economic variables may be relevant for future developments. It is claimed that empirical research based on observations from the past may give us a hint on the importance of these relationships for the future. Yet, as the times are (always) changing, so does the relevance of economic 'laws' and their significance for statements on future developments. It implies that visions about the economic future have to be based on a combination of scientific knowledge, expert intuition, and creativity, with the proviso that this intuition is also the result of experience in the past.

From that perspective, this paper looks at the possible significance of modern futures studies for the economic domain (see Hazeu, 2007). The upshot is that in creating visons on our economic future, the standard way economic science analyses economic phenomena is no longer sufficient to take account of all the complexities that shape future developments. Therefore, lessons from the discipline of futures studies should be learned and included in views on the economic future. This affects the scientific philosophical paradigm of setting up such economic future studies. In this paper, we take for this Roy Bhaskar's philosophy of critical realism as point of reference (Bhaskar, 1998). It implies that we derive our reading of future economic developments not so much from consistent extrapolation of economic relationships of the past, but rather form impressions on what directions future developments in the economy may take. That can be in one future direction, but arguably also in another future direction. We call these impressions, in line with Bhaskar's philosophy, tendencies.

More specifically, this paper considers the role of technology in the economy of the future. Transaction costs economics (TCE) are taken as leading argument in the discussion on how technological progress may affect economic welfare. 
That is because TCE constitutes a link between the traditional neoclassical economic theory where decisions are taken by the perfectly rational "homo economicus" and alternative theories which are skeptical about this paradigm and observe much "irrational" behavior in decision making in the real world. TCE explains that part of seemingly non rational behavior - labeled as bounded rational behavior - can be ascribed to transaction costs which make acquiring full information too costly for a completely rational decision. Addition of this aspect into economic theory extends the explanatory power of standard economic theories to include seemingly non-rational behavior. As especially modern technological developments aim at reducing transaction costs, this provides a neat way to look at future economic developments and on how technological progress may enhance economic welfare. The different technologies, or to be more precise, the various and still unknown consequences of applying these technologies, lead us to distinguish different tendencies for the future. These tendencies are of a more impressionistic character than the commonly used model-based scenarios in futures studies. We label these scenarios "tendencies-based". Therefore, this paper also poses the question "Which are the advantages of designing technology inspired tendencies for the future using TCE and Roy Bhaskar's philosophy of critical realism above the construction of scenarios which give a model consistent extrapolation of past developments, and which are much used in futures studies?"

The contents of the remainder of the paper is as follows. The next section elaborates on the role of rational behavior in describing economic phenomena. Section 3 is about TCE as a bridge between theories that challenge the premise of fully rational behavior. Section 4 describes how critical realism can contribute in this respect to distinguish between various tendencies that are relevant for the design of different economic futures with a focus on technological innovations. Section 5 explains how these tendencies can be used to construct tendencies based scenarios and discusses how such scenarios can be positioned in theories and practice of scenario analysis. Section 6 provides three sets of conflicting tendencies with TCE as a major driver. These tendencies are: (i) production based or service based (innovations which reduce production costs versus innovations which reduce transaction costs); (ii) large versus small (regional versus global; role of trust; pros and cons of large scale versus small-scale supply); (iii) technology and trade - trade as a production technology, pros and cons of splitting up the supply chain internationally. Section 7 shows how in the practical case study of the Sense Glove startup various aspects of our tendencies based scenarios may play a role in the further development of its technology. Finally, section 8 concludes and discusses the answer to the question on how tendencies and scenarios based on these tendencies may be an alternative or complement to model based scenarios in futures studies.

\section{The demise of the rational behavior postulate in economics}

A major reason why there are not invariable scientific economic laws is that the economy is not a closed but an open system. You can study the economy in a laboratory setting and there is even a whole strand of economics that uses laboratory experiments (experimental economics; see Svorenčík and Maas, 2016). However, the real economic world can never be completely mimicked in such an experiment (Kemp and Holmwood, 2003). To cope with that argument against laboratory experiments, nowadays much attention is paid in empirical economic research by so-called natural experiments. These explore where a shock or policy measure only affects part of the population. The difference between the reaction of the affected and the not affected part of the population is considered the effect of the shock or policy measure (see e.g., Rosenzweig and Wolpin, 2000). Moreover, in 2019 the Nobel Prize in economics was awarded jointly to Abhijit Banerjee, Esther Duflo and Michael Kremer "for their experimental approach to alleviating global poverty."Instead of looking at large scale macro-relations, they divided issues of global poverty into smaller, more manageable, questions - for example, the most effective interventions for improving educational outcomes or child health. They have shown that these smaller, more precise, questions are often best answered via carefully designed experiments among the people who are most affected.

However, also in natural experiments, there are always outside influences that make the experiment only partly representative of reality or representative only in the specific environment where the experiment was conducted. A similar proviso holds for empirical relationships that describe economic behavior. For instance, in case disposable income goes up, consumers usually spend more on consumer products, and when the relative price of one type of consumer good goes down, say bananas, commonly the part of bananas in total fruit consumption will go up. That may be more true at the macro level than at the micro level of the individual consumer. Yet also estimates of macro consumption functions do not give a full and invariant picture of consumer behavior. All kinds of unknown other determinants of consumer behavior are included in the function through an error term.

A further problem with these economic relationships, especially when they are used to make predictions on future behavior, is that they are based on fully rational behavior of the homo economicus. This premise of rational behavior is to be challenged. 
Economic assumptions, such as that people are rational and selfish, seem to be more nuanced in practice: consumers do not automatically buy a good whose price falls, and companies are not always efficient, profit-maximizing organizations (see Gluckman, 2016). Unemployment may go up when wage costs increase, or when demand falls. This is one explanation why policy prescriptions to combat unemployment based on standard neoclassical theory will not always be effective.

Therefore, to reflect on the future of the economy and on the extent to which economic science is capable of describing or characterizing it, we need to examine the social and technological changes as major drivers for future developments. With this, we go directly against the views of a very important classical economist, namely Karl Marx, who stated that the economic relations of power form the basis of social relations. Our current society is indeed strongly commercialized and economized, but an important development is that companies are increasingly guided by social, sustainable and even ethical considerations in which building up trust and credibility becomes more important (Carson, 2018). Just think of corporate social responsibility and responsible research and innovation (Von Schomberg, 2013). Apparently, the economy follows societal preferences for welfare that go beyond material welfare.

Regarding the rationality assumption often made in (neoclassical) economics, it is more than interesting to note that quite a number of recent Nobel Prize winners in economics have challenged this traditional view of the homo economics. In 2002, for example, psychologist Daniel Kahneman won the Nobel Prize for his research into the integration of psychological insights into economic science. Kahneman has actually shown that economic behavior can differ much from that of a rationally calculating human being and that systematic errors are made in the calculation of what is rational for one's own interest (Kahnemann and Tversky, 1979). Indeed, it appears that in their economic behavior and decisions people, among other things, have a preference for maintaining the status quo. They value losses much higher than gains in their welfare function and they find it difficult to properly analyze complex situations, especially if future consequences can be uncertain.

Richard Thaler is Nobel Prize winner in economics in 2007. His ideas relate to those of Daniel Kahneman. He demonstrated the effect of "limited rationality, social preferences, and lack of self-control" on individual decisions and on the outcomes of markets. In particular, he has developed the concept of "nudging" that refers to the effective and inexpensive influence of people's choice behavior by giving them certain incentives (Thaler and Sunstein, 2008). It is shown how we can lead people with a soft hand - with a nudge - to better choices, without restricting their freedom of choice. For example, by putting healthy food at eye level in school canteens, or by creating more involvement with pensions by making savings plans default, with a possibility to select other types of plans.

Subsequently in 2009, the winner was Elinor Ostrom who demonstrated that the shared use of natural resources does not have to lead to excessive use of them. She did this by looking at small groups where this does not occur. Based on this, she has developed eight design principles such as joint decision-making by the owners and clarity about what the "commons" are and who the owners are (see e.g., Ostrom, 1990). To conclude, there is a 'tendency' in the economic science to get away from the full rationality assumption in mainstream economics leading to a different view of how economic actors behave and decide and thereby look to and influence the (economic) future.

A major consequence of this tendency of a number of recent Nobel Prize winners to look beyond fully rational behavior in the design of economic theories and the resulting "laws" is that the idea is challenged that prices will, in the end, lead to an equilibrium of supply and demand. May be in some situations the price mechanism can be appropriate to bring about a welfare optimum by equalizing supply and demand, but in other situations quite difference mechanisms and policy interventions are needed to enhance economic welfare.

\section{Transaction cost economics}

The theories of Nobel Prize winners mentioned above are in essence all a (amendment of) criticism of the neoclassical economic theory that is regarded as the standard economic theory. Many economists, policy makers, and politicians base their ideas and especially their expectations on this standard theory. It represents the window through which these economic analyses look at economic reality (Van der Duin, 2019). Often, rational behavior is also the paradigm on which economic projections for the future are based. This is especially true for medium term forecasts of the economy such as are made by the European Commission, by the IMF, by the OECD and in the Netherlands by the CPB (the Netherlands Bureau for Economic Policy Analysis) in its Economic Outlook (see e.g., CPB, 2019). However, as soon as new scientific insights arise, it is time to look at the economy differently, or at least try to stretch up the standard economic theory to have these new ideas incorporated.

In 2009, the Nobel Prize in economics was not only rewarded to Elinor Ostrom but also to Oliver E. Williamson. He received the prize for his work in the field of transaction costs economics (TCE, see Williamson, 1975, 2000, 2008, 2010) for which Coase (in 1991) and North (in 1993) also received the Nobel Prize. 
It seems fruitful to look at the future role of technology in the economy from the perspective of TCE, as done in a report by of the Scientific Council for Government Policy in the Netherlands (WRR) (see WRR, 2003; also Den Butter, 2012). The upshot of this report was that TCE on the one hand gives a hint on how new technologies may influence future welfare, and on the other hand that TCE at least partly provides an explanation why at first sight observed economic behavior does not seem to be rational. In that respect TCE connects the theories of "behavioral economics", as the theories described in the previous section are sometimes labelled, with neoclassical economics.

Transaction costs are interpreted very broadly here. It concerns all costs that are necessary for a transaction to take place. The WRR-report makes a distinction between so-called "hard" and "soft" (intangible) transaction costs. The hard costs are generally perceptible and quantifiable. This concerns transport costs, levies and other tax costs, but also bank costs for financial transactions that are referred to as transaction costs in a narrow sense. However, the soft costs are much more extensive but difficult to determine. It concerns all kinds of information costs, such as on the quality of goods and services but also about the reliability of the trading partner, costs of acquiring knowledge about payment methods, and about written and unwritten rules and standards. It includes the costs of understanding each other and of miscommunication, connecting technical specifications and failure costs, and lobbying and influencing regulations. Global calculations show that in the Netherlands at macro level about half of the national product consists of real production costs and the other half of transaction costs.

Transaction costs arise both in market transactions between companies (transfer of ownership rights) and within companies (transfer of responsibilities) (Coase, 1937; 1992). That is why transaction costs are key to the existence of firms: when transaction costs within the hierarchy are lower than via the market, firms may increase in size. Moreover, for economic welfare it is important to set up institutions in such a way that they hinder transactions as little as possible and thus keep transaction costs low (North, 1987, see also: Ménard, 2005; Antràs, and Rossi-Hansberg, 2009).

The lower the transaction costs, the more transactions are possible. When these transaction costs represent information costs, economic decisions can be based on better information. This represents part of the link between theories on bounded rationality and neoclassical economics. When a decision is to be made, there is always the trade-off between the cost of gathering more information, and the gain that additional information yields for making a better-informed decision. Therefore, information is never complete, but bounded by the costs of collecting information. Obviously from that perspective modern ICT, and new developments in ICT to come, will have an essential influence on transaction costs, and therefore on future economic activity. It is by no means sure that new ICT will always lead to a reduction of the costs of collecting information. Fake news, 'alternative truths, and 'alternative facts', and conspiracy theories on the internet provide a neat illustration on how new technology may even enhance transaction costs and therefore hamper economic activity. This marks the importance of our focus on transaction costs in technological futures research.

In addition, there are differences in preferences at the individual level, making individual behavior difficult to predict. We know from econometrics that at an aggregated level these differences somewhat level out so that empirical economic relationships are better established at the macro level than at the micro level (see e.g., Morgan, 1990). However, here too, the relationships can be very variable over time. Moreover, for the rationality postulate individual preferences are a given, while behavioral economy is correct that it describes how the preferences can be influenced (e.g., by nudging) so that, for example, behavioral relationships at the macro level move more in a desired direction.

\section{Critical realism, futures studies, and tendencies}

The discussion above illustrates that evidence based on economic models constructed in line with standard neoclassical theory does not suffice to draft a central and most probable projection for the economic future. That is especially true when long-term projections are to be made that take into account uncertainties about the impact of new technologies and other unknown developments. Those long-term projections cannot be made on the basis of immutable scientific economics laws because the economic system is an open system and not a closed one. For that reason, we follow Roy Bhaskar's philosophy of critical realism in the presentation of our prospects for the technology driven economy of the future.

Our interpretation of critical realism is that its position of practicing science lies in between the positivist approach with its emphasis on regularities and regression, and social-constructivism with its emphasis on interpretation, and favoring description above causation (Archer et al., 2019). From an ontological perspective critical realism "refers to an objectively knowable, mind-independent reality, whilst acknowledging the roles of perception and cognition" (Hakeem, 2007).

So, on the one hand the purely positivist approach for future-oriented economic policy studies is too tight. The fact that an economic theory cannot be falsified in a certain situation does not mean that it is the best theory in that situation. Alternatively, that all implicit causal relationships in that theory also apply in reality. 
On the other hand, social-constructivism does not offer an appropriate alternative, as in that view every theory is a personal interpretation of reality and therefore empirical evidence does not seem relevant. It makes each narrative on the future equally plausible. As intermediate between positivism and social-constructivism, critical realism can be an effective approach in which quantitative observations from the past and eclectic models of reality offer a view of different visions for the future. In that approach every vision of the future has a logical foundation, but due to yet unknown external developments ("random or unpredictable shocks"), technology-driven changes in preferences and interpretation of information such visions may lead to different impressions or tendencies for the future. TCE can then explain how the availability of information, and the way in which information can be provided and possibly also manipulated, influence economic choice behavior. Given these external, and often technology-driven factors, choice behavior can be regarded as rational, so that here the economic theories based on the rationality postulate can be utilized. In other words, in thinking about the economic future, it is not sufficient to only extrapolate economic laws and empirical relationships based on such laws. It is not sufficient to think in terms of one future. It is preferable to present different visions on the future in the form of impressions or tendencies in line with critical realism.

The field of futures studies is not unknown with critical realism. Sociologist Wendel Bell, one of its founding fathers, "proposes critical realism as an appropriate theory of knowledge for futures studies" (Stevenson, 2003, p.288). In Bell's view, on the one hand this science-philosophical approach enables to develop a futurist critique while on the other hand Bell doesn't challenge the strategic and empiricist assumptions of political and social life" (idem, p.289), leading him to consider futures studies as "action science" (idem.). In addition, McKelvey and Boisot (2009, p.17-18) develop this linkage further by introducing 'transcendental foresight' which builds upon 'transcendental realism' (or 'critical realism') to enable them to distinguish between three types of paths to the future: 1) the future is uncertain not so much because it has not happened yet but because the observer of the future lacks information; 2) future events are being signaled by present developments that might evolve into trends; and 3) the future is discontinuous because of all kinds of developments that can be characterized by as complex, nonlinear, or co-evolutionary.

It goes too far in this article to describe completely the theory of critical realism but for making another link with futures studies it is important to stress the concept of 'tendencies' that is part of critical realism. The term 'tendencies' originates from J.S. Mill who considers in the domain of natural sciences tendencies as multiple possible causes to explain certain empirical phenomena: "There are often several independent modes in which the same phenomenon could have originated... Many causes may produce mechanical motion; many causes may produce some kinds of sensation; many causes may produce death" (1974 (1843), p.239). With regard to tendencies in the social sciences, to which the discipline of futures studies belongs to, J.S. Mill concludes: It is evident that the social sciences considered as a system of deductions a priori, cannot be a science of positive predictions, but only of tendencies" (1974 (1843), p.332). Finally, Reuten and Williams (1989, p.8) consider tendencies as 'normic': “...laws are not open system empirical regularities and open system regularities are not laws". Bhaskar (1975, p.50) himself sees 'causal laws' not as 'powers' but as 'tendencies': “... potentialities which may be exercised or as it were 'in play' without being realized or manifest in any particular outcome". In defining tendencies, Gibson (1983) uses the metaphor of two groups of people each sitting at one endpoint of a rope. If both groups pull equally strong, no movement or change will take place. However, one cannot deny that there are 'forces', or tendencies ${ }^{1}$, and the moment one tendency becomes more powerful, change would indeed become visible, or real. These tendencies, with the present as starting point, may result in and thereby describe alternative possible economic futures, or scenarios, given the uncertainties and shifts in relevant economic mechanisms that shape the future.

In the next section, we will specify this linkage between critical realism and futures studies using the concept of tendency as a framework for building future scenarios.

\section{Tendency based scenarios for the future}

An often-used method, especially regarding economic futures, is to build an economic model, validate that on the basis of historical data and make a forecast. Then, different scenarios are determined by changing the values of a limited set of variables. These model-based scenarios are then (small) deviations from the dominant scenario, which is often called the most likely scenario. However, given the inherent uncertain nature of the future, especially with respect to technological developments and the design of new products and services, model-based scenarios are not able to capture the (required) diversity of possible futures.

\footnotetext{
${ }^{1}$ Different terms that are also being used for describing these 'countervailing powers' are 'trends' and 'counter-trends' (Cramer, Van der Duin and Heselmans, 2016).
} 
Therefore, we propose as an alternative to build scenarios not by carrying a sensitivity analysis based on an economic model, but to use the concept of tendencies (with its trends and counter-trends) so that the scenarios gain in terms of diversity and creativity but still keep their plausibility. Hence: tendency-based scenarios.

Explorations of the future of technology along various lines in the form of tendencies can result in a sketchier and more impressionistic assessment of the future than an exploration based on a single economic theory or model. The concept of scenario analysis comes from the management sciences and was established in the $60 \mathrm{~s}$ and the $70 \mathrm{~s}$. It is grounded in the empirical established notion that most forecasts fail (e.g., Ascher, 1978; Schnaars, 1990, Sherden, 1998; Geels and Smit, 2000). Therefore, as an alternative of predicting one future, it is often better to explore more futures, to enable organizations to anticipate different futures and to learn how to deal with uncertainty (instead of risks). According to Schwartz (1991, p.4) scenarios are a tool “...for ordering one's perceptions about alternative future environments in which one's decisions might be played out". Van der Heijden (1996, p.5), another scenario-guru, divides scenarios into external scenarios being "shared and agreed upon mental models of the external world" and internal scenarios being a personal "anticipation of future states of the interactional world", representing a "causal line of argument" (idem.). Internal scenarios can be considered normative views of the future that are predominantly developed by the person or organization at hand, while external scenarios are positive, representing possible future worlds that might unfold. Both authors consider scenarios not as a means in itself but as a tool for organizations to improve their decision-making processes.

Scenarios can be built in different ways (for an overview, see: Nekkers, 2016). For building external scenarios, the most popular method is by determining which future trends are the most uncertain and at the same time are the most relevant. By taking the extremes of both of the trends with the most uncertainty and highest impact, four quadrants arise, each resembling a specific combination of those extremes. Each quadrant represents the possible consequences of combing these extremes and can be called a scenario, by way of a story about a possible future. Scenarios are then a magnification of combination of tendencies. Essentially, they are a 'thought-experiment', not about what will happen but about what might happen. 'What-if' is the central research question of every scenario-study.

It is plausible that different, conflicting tendencies might simultaneously play a role in the technological future. However, to understand and even experience scenarios build upon tendencies, it is vital to assume that one tendency is taken to the extreme. Thinking in multiple scenarios, as scenario-thinking enables you to do, therefore allows you to take the other tendency into account by taking that one to the extreme.

Scenarios provide internally consistent descriptions of the future that together form an interval of different future uncertainties thereby (hopefully) addressing the subjective and different perceptions and estimations of various managers (Madera, 2019). The advantage of different scenarios of the future, by using the outcomes of different, combined tendencies, is that they describe a certain sub-aspect of economic future 'reality', albeit that the focus on transaction costs actually enables us to see how new technological developments are connected to each other. In addition, scenarios bases on tendencies, instead of a single economic 'law', have the advantage that they indicate which targeted economic policy measures are future-proof and which are not, by testing ('windtunneling') those against the background of these multiple several scenario. This contrasts with having just one scenario for the future, which does not cover the wide variety of possible futures. In addition, just using one scenario would come down (again) to making a forecast of the future of which, as evaluation of forecasts have shown, are often wrong or just present one desirable or most preferred, often confused with the 'most likely scenario' (i.e., forecast) future. Scenarios are therefore not a goal in itself but a means to improve policies and subsequent decisions that take into multiple uncertainties as represented by different tendencies that lead to different future scenarios. This may also be true for teleological scenarios $(\tau \dot{\varepsilon} \lambda \mathrm{o}=$ 'goal') which take a warranted situation or policy goal in the (distant) future as starting point and provides a comprehensive reasoning how this goal or ideal situation can be reached from the present state. In this case of backcasting different tendencies with respect to technology may lead to different paths to reach the final (policy) goal.

To sum up, invariable economic laws do not exist as different economic theories, including those of the Noble Prize winners (see section 3), lead to different visions on the functioning of the economy. ${ }^{2}$ We consider the regularities described by the empirical underpinning of those theories as tendencies by which we can build a scenario-framework that holds many different scenarios, or possible future economic 'realities'.

\footnotetext{
2Another, comparable approach is the one proposed by the economist Nicholas Kaldor, who speaks of 'stylized facts' (inspired by Jan Tinbergen's 'stylization'), which refers to a 'simplified representation of an empirical fact'.
} 


\section{Tendencies}

In this section, we use the concept of tendencies as the foundation of our future scenarios. In particular, we use TCE, how that might affect various 'futures', and we distinguish thereby three tendencies:

1.Innovation will be predominantly product-based or innovations are predominantly service-based.

2. The scale of supply will become predominantly small or it will become predominantly big.

3. Supply chain management will become predominantly global or it will become predominantly local.

\subsection{Innovation: production-based or service-based}

In neoclassical theories of economic growth technological innovations usually relate to improvements of products and services, or to new product and services, which enhance either labor productivity or total factor productivity. Often such innovations are the result of investments in R\&D. However, for a view of the economic future from the perspective of TCE, technological innovation that results in a reduction in transaction costs is also important. In that case, more trade transactions can take place and productivity can increase as the possibilities of (international) specialization can be better utilized. These service based innovations that enhance trade transactions through lower transaction costs can be labelled trade innovations. An example that brought great prosperity to the Netherlands in its so-called Golden Age (second half of the $17^{\text {th }}$ century) is the fact that Dutch sailing ships had a keel. As a result, it was possible to sail against the wind and the transport of merchandise was not dependent on favorable wind. More recent examples of trade innovations are the container and the pallet. Worldwide use of standard-sized containers, which means there is no need to transfer goods, has resulted in savings in (hard) transaction costs that have increased (world) trade many times more than all free trade agreements or the GATT combined. Bernhofen et al. (2016) provide support for the view of containerization being a driver of 20th century economic globalization. Their estimates suggest that containerization did not only stimulate trade in containerizable products (like auto parts) but also had complementary effects on non-containerizables (like automobiles).

However, nowadays, and probably also in the near future, it is mainly innovations in the use and utilization of ICT that reduce transaction costs and thereby promote trade. Examples are the various types of bar codes (numeric, alpha numeric, two-dimensional) as standards that support the registration of goods flows and information about them. Bar codes also speeded up grocery checkout at the checkout counter in supermarkets. It implied a reduction of transaction costs for the clients and a gain of efficiency for the cashier and therefore for the supermarket. Thanks to new technological developments, the payment system has become considerably more efficient in recent times: for example, the way in which iDeal facilitates payments in the internet trade in the Netherlands (Den Butter and Mallekoote, 2019). Another example is the Adyen company, which obtained a huge market value at the stock exchange because it connects all sorts of payment systems and thus lowers transaction costs for customers. In this area of 'Fintech', many innovations are still on the horizon: for example, consider the plans of the Libra consortium to arrive at a worldwide payment currency, in which people can develop their own payment applications thanks to open source software. However, such a new payment method from the regulatory point of view still has some snags (see e.g., Den Butter and Middendorp, 2019) and it makes the present initiative questionable. More in general, the need for regulation and safeguarding privacy may provide a counterweight to implementation of various kinds of innovations in ICT and the social media (see e.g. Susskind, 2018; Carney, 2019).

\subsection{The scales of supply: small or big}

Another way of looking at possibly diverging economic futures as a result of technological innovations is to consider the extent to which the delivery of goods and services in the future will either take place on a large scale, via global business agglomerates, or on a small scale, through small providers or through cooperative associations. This question of future tendencies is inspired by a small futures studies project at VU University, recorded on tape (see VU Connected, 2013). Here the idea was to come up with two opposing visions where one part of the experts argued in favor of one tendency, and the other provided arguments for the opposite tendency. Yet in reality there is no guarantee that the arguments of one group of experts becomes reality, and that one of the tendencies will be dominant.

A major argument that large-scale delivery of goods and services will become more and more important in the economic future is that it exploits economies of scale. A major lesson from TCE is that such size increase of providers may enhance standardization which is important in reducing transaction costs. With standards you only need to get information about that standard once. The more often you use the standard, the easier it is to use and the lower the transaction costs per transaction. Yet, there is a danger of being 'trapped' in a certain standard. A well-known example is the QWERTY keyboard: much more efficient keyboards are available, but everyone is used to the order of the characters on the QWERTY keyboard. Economies of scale and dominant standards imply in some cases a "winner takes all" situation so that there is a monopoly in the production and delivery of goods and services, which hinders competition. 
This seems to be happening to an increasing extent with the major technology companies (BigTechs: Google, Microsoft, Facebook, Apple). Another reason for this tendency to gain importance is that it is easier for large companies to build up a reputation for reliability, whereby the information costs for assessing the reliability of the company are lower. A well-known logo and company name, supported by appealing advertising and use of social media, are very helpful in this respect. Reputation of reliability is also guaranteed by the fact that a loss of reputation is very expensive for large companies - although such a loss of reputation still occasionally occurs.

From the perspective of TCE, the advantage here is that information about reliability and quality is obtained through social contacts, and that the preservation of reputation is regulated through social control. This applies, for example, to local cooperation in the sharing economy. In addition, the human dimension promotes this tendency to small-scale production and cooperation. A neat recent example in the Netherlands is the concept of "Herenboeren" (Gentlemen farmers) where local cooperations of citizens are established who collectively own an ecofriendly farm and employ a farmer to do the work. Decisions on what to grow and harvest are made in the meetings of cooperation members. The vegetables, fruit and meat from the farm are distributed to the about 150 to 200 farm owners based on subscription fees (see Farming Communities, 2019). Moreover, there is a possibility for owners to volunteer and help the farmer e.g. in harvesting and distribution. It enhances trust and togetherness between the owners and in that way contributes in reducing transaction costs in the community. It is a kind of creating a feel for commons in the vein of Ostrom (Ostrom, 1990).

Characteristic for the hybrid nature of the small-scale sharing economy is that standard procedures are often used in arranging cooperation that are available through large intermediaries. A typical example is that the neighborhood app Nextdoor (with which neighbors can keep each other, the municipality and the police informed) is a major commercial success, and is according to Sawers (2019) valued at 2.1 billion dollars. The reason is that even here such standard procedure via the internet results in much less information costs than when neighbors arrange it via a local cooperative network on their own. Other examples of commercial companies that focus on the local sharing economy are Snappcar (renting a car from your neighbors), Peerby (lending tools), Thuisafgehaald (meals at neighbors) and BlaBlaCar (getting lifters). An example from a somewhat different perspective is Alibaba in China, which has given all kinds of small producers in China the opportunity to arrange their products through their own web store within the Alibaba specifications, so that they can deliver their products throughout China (and possibly worldwide in the future). Alibaba also takes care of the payment system and maintaining the reputation of both suppliers and customers. (e.g.,Makinen, 2016).

\subsection{Global or local in supply chain management}

An important consequence of reducing transaction costs is that it enhances the benefits from specialization. Illustrative of this is that, thanks to transaction costs reducing innovations, production chains are being split into more and more links. This happens within companies, both within their own country and internationally, but also parts of the chain are more frequently being outsourced to other companies. These different ways of organizing the production chain, the "supply chain management", are determined by those "make or buy" and location decisions that entail the lowest total costs in the supply of goods, services or experiences. There is always a trade-off between production in-house, or to outsource part of the chain. Outsourcing is more advantageous when the additional transaction costs of linking the outsourcing to one's own production process are lower than the costs of producing or delivering the part to be outsourced in-house. As a major reason for outsourcing is that total costs go down, it implies that productivity in the home country may increase. It is the productivity effect of international specialization (Grossman and Rossi-Hansberg, 2008) that comes as the result of transaction costs reducing innovations.

Obviously, the internationalization of production has consequences for the types of jobs in the home country of companies that act as orchestrators of the supply chain. Berghuis (2014) and Berghuis and Den Butter (2017) illustrate this shift in jobs by distinguishing between jobs that are directly aimed at production - within the links in the chain and jobs that, in a broad sense, aimed at connecting links in the chain. Categorization and measurement of these two types of jobs shows that the number of jobs of those who coordinate and orchestrate the supply chain is continuously increasing relative to the sheer production jobs. In addition, the case studies in Berghuis and Den Butter (2017) indicate that outsourcing abroad leads to the loss of production jobs in the home country. However, on balance there are no job losses as the additional jobs that are needed to coordinate and orchestrate the international supply chain more than compensate for that loss of sheer production jobs.

The arguments above suggest that technological developments in ICT will favor a tendency of further internationalization of production and globalization. However, the recent past also provides ample arguments for a tendency in the other direction, where the pros of globalization are crowded out by cons. 
The first argument relates to the upcoming surge of nationalism, where countries are protecting their home economies from competition abroad, regardless of the negative consequences of such policy for welfare. Of course, Trumps "America first" is the most prominent example. In addition, the Brexit and the difficult support for the EU are part of this tendency. A second argument is that up to now a reason for outsourcing was low wages in the countries of outsourcing. Most tasks to be outsourced relate to routine jobs that in the future with advanced technological development can be done by computers and robots at home.

A third argument stems from environmental policies to combat climate change. Sharper regulation and rules for reducing greenhouse gas emissions and waste will limit the (labor) productivity gains from technological progress. Environmental policy and societal responsible behavior of industry will induce that technical innovations are more and more directed at environment and waste saving technological progress than at labor or capital saving. Here there a distinction is to be made between new technologies that reduce the use of fossil materials and technologies that enhance circularity in the economy. In this context McCarthy et al. (2018) present a critical survey of recently developed models of circularity. Den Butter and Webers (2018) provide a conceptual model with both energy saving and waste reducing technological progress and show applications in case studies. Actually the recently observed slowdown of productivity growth can partly be ascribed to the influence of policies to combat global warming (which enhance global welfare in a broad sense; see e.g., Aitken, 2019). Therefore, it is at least necessary to correct measures of (total) factor productivity for technical measures that reduce the use of the environment (OECD, 2016). Therefore, future studies on the role of technological innovation should balance between these pros and cons of organizing production on a global scale.

\subsection{Tendency-based scenarios}

Combining the three opposite tendencies discussed above can give rise to eight different scenarios where each of the three tendencies is considered at its extreme (and as a scenario-axis) and combined with one of the other two tendencies. Eight scenarios, however, are difficult to distinguish from each other and not very practical for making strategic or policy decisions. Therefore, we combined two tendencies, namely scales of supply (small or big) and supply chain management (global or local), which seem to be somewhat correlated, giving four scenarios:

Innovation: service-based

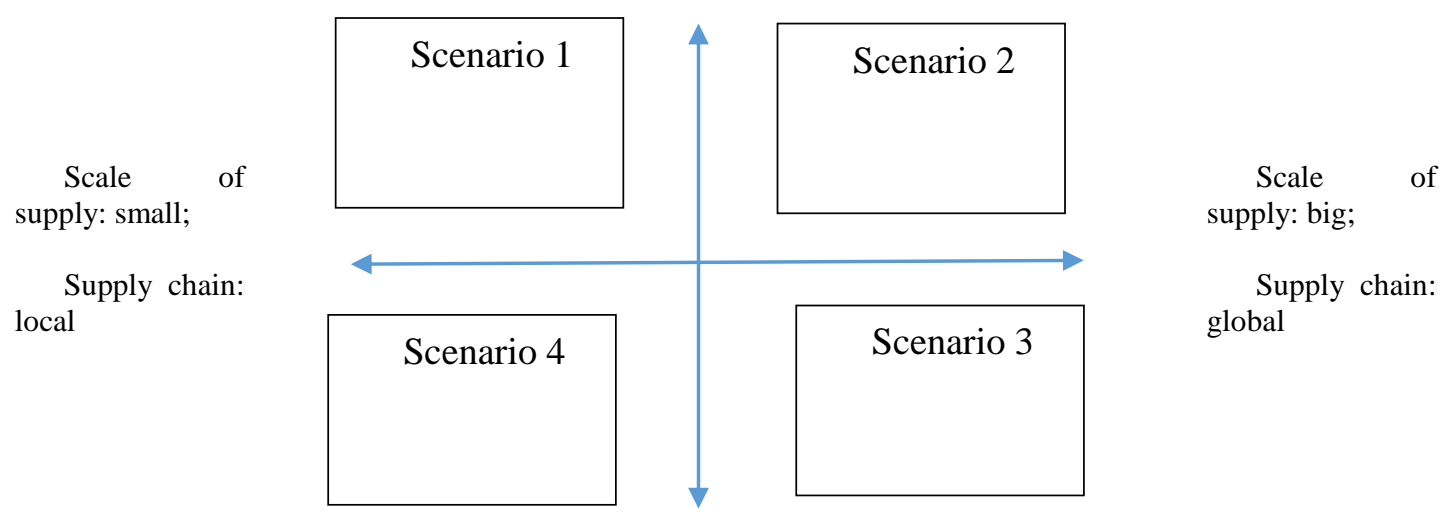

Innovation: production-based

Figure 1: Four scenarios based on combining three tendencies.

Figure 1 shows the four scenarios resulting from combining these tendencies. For our argument it is important to note that Scenario 3 is the scenario that is reflecting most the economic 'laws' of the standard neoclassical theory and can be considered 'business as usual- scenarios that government officials, policy-makers, managers, and entrepreneurs already take into account. A bit less usual is Scenarios 4 where the neoclassical idea of production costs reducing technological 
progress still holds, but where in fact production only takes place on a local scale. This may be regarded as illustrating the consequences of protectionist policies.

Scenario 1 and Scenario 2 diverge most from the standard model based scenarios as they focus on the role of transaction costs and the lessons from TCE that are usually neglected in scenario analyses. In this respect, Scenario 1 can be considered the most extreme scenario because it is based on two tendencies that are contrary to the tendencies implicit in model based scenarios emanating from standard neoclassical economic theory.

From that perspective, it is more than worthwhile to further explore Scenario 1 and see what strategic decisions the entrepreneurs of Sense Glove (see section 7) need to take if this might unfold in the future. It contrasts most with the usual model based scenarios and therefore would be a much more rigorous sensitivity test for such start-up than the other scenarios. 'Windtunneling' their business proposition in this scenario gives the entrepreneurs of Sense Glove the opportunity to prepare for an unthinkable, but not implausible future.

If we take a more detailed look at Scenario 1, we can imagine the following future story:

In this future economy the business models of companies focuses on making money about of delivering services, not on top of products but instead of selling products. Customers no longer want to possess 'stuff' but want to have access to 'stuff'. For instance, people do not own cars any more but have subscriptions that allow them to 'rent' a car that is nearby (in their neighborhood). In addition, the focus on service innovation also put customers and their needs in the core of innovation processes. No longer do the most innovative companies hold the most patents or have the largest $R \& D$-facilities. Knowing the real insights of the current and future needs of your customers and how to serve them during the adoption process of innovations is the most important success factor for businesses. The focus on services and lowering the user costs for customers is in line with local focus of companies. 'Think global, act local' has been replaced by 'Think local, act local'. Global presence may no longer be a sign of strength for companies. Better is it to be physically close your customer who prefer local products and services above those who are produced elsewhere and have to be shipped from far places. The increasing need and urgency to be economical with energy and reduce the emission of $\mathrm{CO} 2$ is an important driver for this change in transportation. It is already apparent that companies that still have global presence fanatically try to give their products, services, and brands a local flavor and try to adapt their (globalized) standard products to local circumstances.

\section{The Sense Glove case study}

The case study is about the Dutch startup Sense Glove which operates from the YesDelft!, a leading tech incubator at the Delft Technical University (TU Delft).Two former TU Delft students in strategic product design founded this startup under the name Adjuvo Motion. Initially a prototype of a light, compact and modular robotic brace was developed which could be used for cost-effective rehabilitation of people with paralysis of the arms due to a stroke. In a later stage, the focus was on rehabilitation of the hand and the company changed its name into Sense Glove. However, at that time it became clear that getting into the therapeutics market, especially for a starting business, was going to be next to impossible (see: Arocho, 2019). Therefore, Sense Glove changed its focus and potential market: if its system of robotics and motors could be used to open hands for therapy patients, the same method could be flipped around. The motors could be utilized to resist a closing hand and with the right tension, it could simulate the action and actually be felt. Now Sense Glove offers a patented robotic hand where its unique low latency force-feedback system enables the user to feel the shape and density of virtual objects. Due to the precise sensor based tracking of each joint in the hand, every interaction using the Sense Glove renders a virtual reality to feel like a physical environment. The Sense Glove can be used as force-feedback controller for virtual and augmented reality or as input device for tele-robotics. Although in future the Sense Glove can be adapted for consumers e.g. in VR and AR games, today application is mainly in the field of B2B. The customer list of Sensed Glove consists of several automotive, research and robotics companies from around the world. These include VW, Airbus, Google Deepmind and Honda.

How does the case of Sense Glove relate to the various tendencies described above? Sense Glove offers a technically highly advanced product, which, in the terminology of traditional economic growth theory, can be considered to contribute to technological progress, and therefore to economic growth. However, it is not only the hardware technics that is important for Sense Glove's business model. Also, and even mainly, the software steers the glove in applications warranted by the customers. It requires much interaction with the customers and learning about how the feel for certain objects can be standardized in the software at use. From that perspective this case illustrates how good communication and reducing transaction costs go hand in hand (to use an appropriate wording) with mere technical progress. Before the technology of Sense Glove can be made profitable, ample information costs are to be made to find out how the product can best be used in practice. Therefore, it is not simply the contribution to a new labor saving production technology, which would have been more or less the case with the use of the brace or glove for rehabilitation purposes. 
The move to using the glove in VR and AR makes it compare with the early days of the personal computer or the mobile phone. In those days, there was no much insight either into the way these devices were to be used in future.

Nowadays it is yet not certain whether Sense Glove will survive its startup phase and whether the founders and other stakeholders will in the end be able to make it a valuable company. In that respect the case of Sense Glove acts more as an illustration of entrepreneurship than as an example of rational behavior in line with the neoclassical theory of the firm and with growth theory. We believe that the question whether Sense Glove will become a valuable company will be decided to the extent it is able balance exploitation and exploration over time and simultaneously (Tran, 2015).

In addition, we think that in particular they need to anticipate and adjust to unknown futures, as described in Figure 1. Because Scenario 1 might be the most extreme scenario we know for exploring what Sense Glove could (or should) do from a strategic point of view in order to build up a profitable business in the case it ends up in future Scenario 1:

As the Sense Glove is a technically advanced product, and the obtained worldwide patent relates to its technical design, in this possible future economy it would require them to build up much more market-related capabilities. As this scenario is very local-orientated, being close to potential customers and developing deep market insights will become essential to their company. Having the right business model that suits the needs of local customers will be more important than delivering a product that is the best form a technical perspective. Talking about products, in this scenario adding services to your products is key and it can be safely assumed that in this possible economic future Sense Glove needs to align with the trend of 'servitization', being prepared to make more money with delivering services around its product than with the product itself. In addition, the business model of Sense Glove should take into account that customers do not want to own the product but want to have easy access to it. They need to experiment with different ways of leasing their product thereby making sure that the best way to do this is by adopting a local approach. Being close to end-users, almost in a physical way, is the best way to discover the specific service requirements. In fact, the further development of Sense Glove in this future will require much interaction between the design of the product and the software being used for the product and the service of the 'Sense Glove'. Sense Glove should be cautious not to speed up the scale of their production and supply to fast and on a too large geographical scale, since due to local differences in customer preferences, this might become rather inefficient. It would be better to start local and only expand if it is able to customize its product and services to new and different local tastes.

\section{Conclusions}

Insight into the role of transaction costs (TCE) provides a good starting point for an economic exploration of the significance of technological innovation for future production, trade, and welfare. Of course, this mainly concerns new techniques that directly influence transaction costs and are therefore important for the organization of the production process, both at the company level and at the macro level. In addition, innovations that directly affect production and thereby increase productivity within the links of the production chain can have consequences for the way in which production is organized and for the relationship between direct production costs and transaction costs.

This exploration resulted in outlining tendencies for possible future developments in the various aspects of the economy we discussed. This way of limiting ourselves to tendencies for the construction of future scenarios made it easier to account for the known unknowns for the future.

The tendencies distinguished by us in this paper are of a more impressionistic character than the commonly used economic theories and model based scenarios in futures studies. It validates our answer to the research question that constructing technology inspired tendencies for the future using TCE and Roy Bhaskar's philosophy of critical realism (or transcendental realism) provides an alternative for the construction of scenarios that give a model consistent extrapolation of past developments. However, these tendencies also evoke discussions on which of the alternatives seems most probable for the future, or most warranted. The upshot is that these tendencies can be combined to scenarios, which we call tendency-based scenarios. They can offer a more comprehensive vision on the way technological development may take place and interact with the economy, than the traditional model based scenarios. This way of constructing scenarios is illustrated for a startup firm that develops a glove that can make the digital world feel real. It is shown that for this firm a tendency-based scenario is most appropriate which deviates considerably from the scenario that a model based scenario inspired by traditional neoclassical economic theory would yield.

\section{Literature}

Aitken, A. (2019). Measuring welfare beyond GDP. National Institute Economic Review, 249, R3-R16.

Antràs, P. \& Rossi-Hansberg, E. (2009). Organizations and trade. Annual Review of Economics, 1 (1), $43-64$.

Arocho, C., (2019). Senseglove gets a feel for VR. [Online] Available:

https://bits-chips.nl/artikel/senseglove-gets-a-feel-for-vr/ (September 24, 2019) 
Ascher, W.A. (1978). Forecasting. An Appraisal for Policy-Makers and Planners, The John Hopkins University Press, Baltimore.

Bhaskar, R.A., (1998). The Possibility of Naturalism (3rd ed.). London: Routledge.

Berghuis, E. (2014). Labour market consequences of international fragmentation of production. PhD thesis, VU University Amsterdam, June 12 2014.

Berghuis, E. \& Den Butter, F.A.G. (2017). The transaction cost perspective on international supply chain management; evidence from case studies in the manufacturing industry in the Netherlands. International Review of Applied Economics, 31 (6), 754-773.

Bernhofen, D.M., El-Sahlid, Z. \& Kneller, R. (2016). Estimating the effects of the container revolution on world trade. Journal of International Economics, 98, 36-50.

Butter, F.A.G. den (2012). Managing Transaction Costs in the Era of Globalization, Advances in New Institutional Analysis Series. Cheltenham: Edward Elgar.

Butter, F.A.G. den, \& Webers, H.A.A.M (2018). Eco efficiency and circular production: cases from the Netherlands' eastern region, Ch. 20 in Harry Lehmann (Ed.), Factor X, Challenges, Implementation Strategies and Examples for a Sustainable Use of Natural Resources (pp. 305-316). Springer International Publishing.

Butter, F.A.G. den, \& Mallekoote, P.M. (2019). The payment system as a public good? Lessons learned in the Netherlands. Journal of Payments Strategy \& Systems, 12 (4), 304-313.

Butter, F.A.G. den, \& Middendorp, J. (2019). De Libra: goed, geld of goed geld? (Libra, good, money or good money?). Me Judice, August 7th, 2019.

Carney, M. (2019). Enable, empower, ensure. A new finance for the new economy. Speech, 20 June 2019, Bank of England.

Carson, P. (2018). How Calculative are Managers When Evaluating Signals? An Empirical Examination of Signaling Theory in Trust Formation. Journal of Business \& Economic Policy, 5 (4), 54-64.

Centraal Planbureau (CPB) (1992). Scanning the Future; a Long-term Scenario Study of the World Economy, 19902015. Den Haag: Sdu Uitgevers.

Centraal Planbureau (CPB) (2010). The Netherlands of 2040. Den Haag: Sdu Uitgevers.

Centraal Planbureau (CPB) (2019).Middellangetermijnverkenning 2022-2025,November 18, 2019, Den Haag.

Coase, R.H. (1937). The nature of the firm. Economica, 4 (16), 386-405.

Coase, R.H. (1992). The institutional structure of production. American Economic Review, 82(4), 713-719.

Cramer, T., Van der Duin, P.A. \& Heselmans, C. (2016). TrendAnalysis. In P.A. van der Duin (Ed.), Foresight in organizations. Methods and tools (pp. 40-58).New York:Routledge.

Duin, P. van der (2019). Over economische wetmatigheden en de toekomst, in S. den Hartog de Wilde, Bioprinters, Grondstof Rotondes en Braininternet?: Hoe wij produceren, consumeren en herverdelen in 2050 (pp. 23-27). Den Haag: Stichting Toekomstbeeld der Techniek.

Farming communities (Herenboeren) (2019). Our Theory of Change: A road towards nature-driven, socially connected, economically supported food systems for everyone in the Netherlands. [Online] Available: https://farmingcommunities.org/ (November 2019).

Geels, F.W. \& Smit, W.A. (2000). Failed technology futures: pitfalls and lessons from a historical survey. Futures, 32, 867-885.

Gluckmann, R. (2016). Management lessons from a Kodak career. Journal of Business \& Economic Policy, 3 (4), 9-12.

Gibson, Q. (1983). Tendencies. Philosophy of Science, 50 (2), 296-308.

Hartmann, D. (2007). Astronomy: observing the past and predicting the future. In P. van der Duin (Ed.), Knowing tomorrow? How science deals with the future (pp. 167-182). Delft: Eburon.

Hazeu, C. (2007). Dealing with the future in economics. In P. van der Duin (Ed.), Knowing tomorrow? How science deals with the future (pp. 57-68). Delft: Eburon.

Heijden, K. van der (1996). Scenarios. The art of strategic conversation. Chicester: John Wiley \& Sons.

Kahneman, D. \& Tversky, A. (1979). Prospect theory: An analysis of decision under risk. Econometrica, 47, $263-291$.

Kemp, S. \& Holmwood, J. (2003). Realism, regularity and social explanation. Journal for the theory of social behavior, 33 (2), 165-187.

Madera, A.G. (2016). Ways of People's Estimating Uncertain Quantitative Factors for Decision-Making in Economy and Business. Journal of Business \& Economic Policy, 6 (3), 48-51.

Makinen, J. (2016). Chinese e-commerce giant Alibaba connects rural residents to online shopping. Los Angeles Times. [Online] Available: http://www.latimes.com/world/asia/la-fg-china-rural-economy-20160403story.html. (April 17, 2016).

McCarthy, A., Dellink, R. \& Bibas, R. (2018). The macroeconomics of the circular economy transition: a critical review of modelling approaches. OECD Environment Working Papers, 130. Paris: OECD Publishing. 
Ménard, C. (2005). A new institutional approach to organization, Ch. 12 in C. Ménard and M.M. Shirley (Eds.), Handbook of New Institutional Economics (pp. 281-318). Berlin: Springer

Mill, J.S. (1974 (1843)). The Collected Works of John Stuart Mill, Volume VIII - A System of Logic Ratiocinative and Inductive Part II. Edited by John M. Robson. Toronto: University of Toronto Press; London: Routledge and Kegan Paul

Morgan, M.S. (1990). The History of Econometric Ideas. Cambridge UK: Cambridge University Press.

Nekkers, J. (2016). Developing scenarios. In: P.A. van der Duin (Ed.), Foresight in organizations. Methods and tools (pp. 11-39). New York: Routledge.

North, D. (1987). Institutions, transaction costs and economic growth. Economic Inquiry, 25(3), 419-428.

OECD (2016). Greening productivity measurement; environmentally adjusted total factor productivity growth. OECD Policy Perspectives, September 2016.

Ostrom, E. (1990). Governing the Commons: The Evolution of Institutions for Collective Action. Cambridge, UK: Cambridge University Press.

Reuten, G. \& Williams, M. (1989). Value form and the state. The tendencies of accumulation and the determination of economic policy in capitalist society. London: Routledge

Rosenzweig, M.R. \& Wolpin, K.I. (2000). Natural "Natural Experiments" in Economics. Journal of Economic Literature, 38 (4), 827-874.

Sawers, P. (2019). Neighborhood social network Nextdoor raises $\$ 123$ million at $\$ 2.1$ billion valuation. Venturebeat. [Online] Available: https://venturebeat.com/2019/05/14/neighborhood-social-network-nextdoor-raises-123million-at-2-1-billion-valuation/ (May 14, 2019).

Schnaars, S.P. (1990).Megamistakes. Forecasting and the Myth of Rapid Technological Change. The Free Press, New York.

Schwartz, P. (1991). The art of the long view. Planning for the future in an uncertain world. Chichester: John Wiley \& Sons.

Sherden, W.A. (1998). The Fortune Sellers. The Big Business of Buying and Selling Predictions. John Wiley \& Sons, New York.

Stevenson, T. (2003). Wendel Bell: critical realism in studying the future. Futures, 35, 285-295.

Svorenčík, A. \& Maas, H. (2016). The Making of Experimental Economics; Witness Seminar on the Emergence of a Field. Springer, Cham, Heidelberg, New York.

Susskind, J. (2018). Future Politics Living Together in a World Transformed by Tech. Oxford University, Oxford.

Thaler, R.H. \& Sunstein, C.R. (2008). NUDGE; Improving Decisions about Health, Wealth, and Happiness. New Haven \& London: Yale University Press.

Tran, H.Q. (2015). Organizational Ambidexterity in Small Firms: The Role of Top Management Team Behavioral Integration and Entrepreneurial Orientation. Journal of Business \& Economic Policy, 2 (4), 31-39.

Von Schomberg, R. (2013). A vision of responsible research and innovation. In R. Owen, J. Bessant \& M. Heintz (Eds.), Responsible innovation. Managing the responsible emergence of science and innovation in society (pp.51-74). Chichester: John Wiley \& Sons.

VU Connected (2013). Documentary "Het verdwijnen van bezit" ("loss of property"). [Online] Available: https://www.youtube.com/watch?v=1gNIT3SQdEE (November 4, 2013).

Wetenschappelijke Raad voor het Regeringbeleid (WWR) (2003). Nederland Handelsland; Het Perspectief van de Transactiekosten. Rapporten aan de Regering, 66. Den Haag: Sdu Uitgevers.

Williamson, O.E. (1975). Markets and Hierarchies: Analysis and Antitrust Implications. New York: Free Press.

Williamson, O.E. (2000). The New Institutional Economics: taking stock, looking ahead. Journal of Economic Literature, 38(3), 595-613.

Williamson, O.E., (2008). Outsourcing: transaction cost economics and supply chain management. Journal of Supply Chain Management, 44 (2), 5-16.

Williamson, O. E. (2010). Transaction cost economics: the natural progression. American Economic Review, 100(3), 673-690. 